\title{
Peri-implantitis: a new disease!
}

\section{Editorial}

Dental implants have became a popular instrument in the replacement of lost teeth during the last five decades. In the late sixties and early seventies of the past century, Branemark et al. ${ }^{1} \&$ Schroeder et al. ${ }^{2}$ were the first to insert scientifically-based titanium screws in the human jawbone. The high survival rate, reported in several 10year follow-up studies, has led to the general acceptance and use of dental implants in prosthetic rehabilitations. But, every year more than 140,000 dental implants get lost, i.e. 1 implant every 4 minutes, mostly because of peri-implantitis (i.e. inflammatory lesion, affecting the implant-supporting bone). Moreover, one out of 5 patients develops peri-implantitis, whereas peri-implant mucositis (i.e. inflammatory lesion, limited to the surrounding mucosa) is a common phenomenon among patients treated with dental implants, affecting nearly $80 \%$ of them. Due to the fact that dental implants are only fashionable since 50 years, we can state that these infections rather "new".

As with periodontal disease, also peri-implant mucositis and periimplantitis are of bacteriological origin. Gram-negative anaerobic microorganisms are present in all these diseases. Ultimately, these infections lead to loss of bone, supporting the implant or even finally to complete implant-loss. Therefore, the use of implants in partially edentulous patients needs extra attention; because bacterial translocation from periodontally infected teeth to pristine titanium implant surfaces is generally accepted. ${ }^{3}$ Placing implants in patients with ongoing or untreated periodontitis is therefor an iatrogenic maltreatment!

Although misleading, occlusal overload on prosthetic reconstructions, is not considered as peri-implantitis: the bone loss is not caused by bacteria and the radiological examination shows a radiolucent zone, parallel to the implant surface. In case of overload, mostly bio-mechanical complications are detected (chipping of the porcelain, fractures of internal components or even complete implant fractures). ${ }^{4}$

\section{Three types of peri-implantitis (PI) are determined:}

a. Early PI: pockets $\geq 4 \mathrm{~mm}$ and bone loss $<25 \%$ of the implant length.

b. Moderate PI: pockets $\geq 6 \mathrm{~mm}$ and bone loss $25-50 \%$ of the implant length.

c. Advanced PI: pockets $\geq 8 \mathrm{~mm}$ and bone loss $>50 \%$ of the implant length. On the other hand, distinction is made between $4 / 3 / 2 / 1$ wall bone-defects and dehiscences.

Studies showed that a history of former periodontitis is a cofactor for developing peri-implantitis, as well as plaque (bad oral hygiene), smoking and the lack of recalls. It may therefor be stated that without a proper recall-programm, no implants should be placed. The oral hygiene compliance is also determined by the design of the prosthetic reconstruction: accessibility around the implants should be safeguarded. Finally, systemic diseases as diabetes mellitus, osteoporosis, alcoholism and stress can play a role. Also local factors have to be taken into consideration: implant surface roughness, connection implant-abutment, cement rests by crowns and bridges and the lack of keratinsed mucosa around the implant.
Volume I Issue 3 - 2014

\author{
Curd Bollen \\ Department of Periodontology Halitosis Implantology, Oral \\ Clinical Center, Netherlands
}

\section{Correspondence: Curd Bollen, Department of}

Periodontology Halitosis Implantology, Oral Clinical Center, Eyckholtstraat I-6I I6 BR Roosteren, Netherlands, Tel 00-3165366-6824, Email curdbollen@me.com

Received: July 08, 2014 | Published: July 9, 2014

Diagnosis of the infection is generally done by probing (preferably with a plastic probe), radiological examination (when increasing pockets are detected and/or pus, or at least every 5 years). Microbiological testing is also an option, although the use of systemic antibiotics, as conclusion of the test results is never an option. Recently a chairside aMMP-8 test was developed, which helped to detect active boneless around implants in less than 15 minutes.

Although prevention is always better than cure; the therapy of mucositis and peri-implantitis is becoming a "new" discipline in oral health, mostly adapted from the concepts used for treating periodontal diseases. Both non-surgical (cleaning with teflon instruments/ airflow/ laser/ disinfection with chloorhexidine) and surgical approaches (resection/ bone regeneration) are employable for the treatment of the problem. However, robust clinical data are lacking on this topic. Nevertheless, the actual research activity in this field is high, so that new data are continuously produced with the expectation of clear guidelines for the treatment in the near future. ${ }^{5}$ Supportive care and maintenance are recognized as being the most important aspects for preventing peri-implant diseases. Especially former periodontitis patients should be recalled at least 3 or 4 times a year. Information for clinicians as well as for patients needs to be instructed on a much larger scale.

\section{Acknowledgments}

None.

\section{Conflict of interest}

The authors have no declared potential conflicts of financial interest, relationships and or affiliations relevant to the subject matter or materials discussed in the manuscript.

\section{References}

1. Branemark PI, Adell R, Breine U, et al. Intra-osseous anchorage of dental prostheses. I. Experimental studies. Scand J Plast Reconstr Surg. 1969;3(2):81-100.

2. Schroeder A, Pohler O, Sutter F. Tissue reaction to an implant of a titanium hollow cylinder with a titanium surface spray layer. SSO Schweiz Monatsschr Zahnheilkd. 1976;86(7):713-727.

3. Quirynen M, De Soete M, van Steenberghe D. Infectious risks for oral implants: a review of the literature. Clin Oral Implants Res. 2002;13(1):1-19. 
4. Isidor F. Loss of osseointegration caused by occlusal load of oral implants. A clinical and radiographic study in monkeys. Clin Oral Implants Res. 1996;7(2):143-152.
5. Lindhe J, Meyle J. Group D of European Workshop on Periodontology (2008) Peri-implant diseases: consensus report of the sixth european workshop on periodontology. J Clin Periodontol. 2008;35(8 Suppl):282-285. 